centre for analysis of risk and regulation An ESRC Research Centre

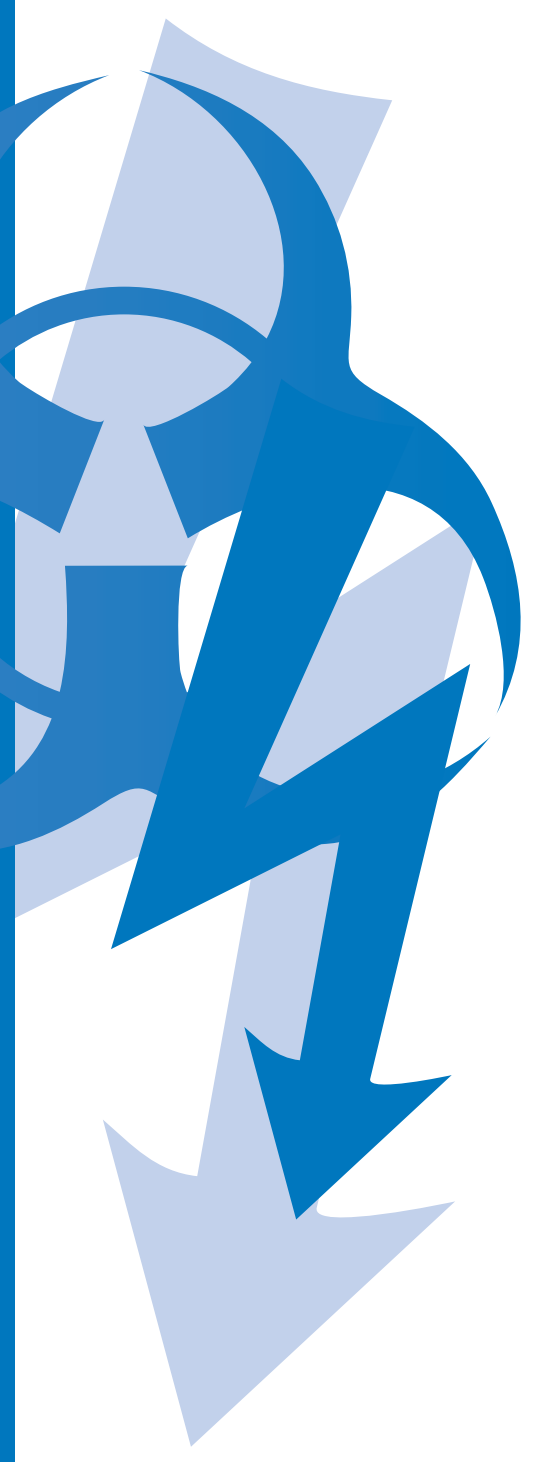

Self-Reporting Untoward Events to External Controllers: Accounting for Reporting Failure by a Top-Tier Chemical Plant

Julien Etienne 


\title{
Self-Reporting Untoward Events to External Controllers: Accounting for reporting failure by a top tier chemical plant
}

\author{
Julien Etienne
}

\section{Contents}

Abstract 
The work was part of the programme of the ESRC Centre for Analysis of Risk and Regulation.

\author{
Published by the Centre for Analysis of Risk and Regulation at the \\ London School of Economics and Political Science \\ Houghton Street \\ London WC2A $2 \mathrm{AE}$ \\ $\mathrm{UK}$
}

(c) London School of Economics and Political Science, 2010

ISBN 978-0-85328-432-1

All rights reserved.

No part of this publication may be reproduced, stored in a retrieval system, or transmitted, in any form or by any means, without the prior permission in writing of the publisher, nor be otherwise circulated in any form of binding or cover other than that in which it is published and without a similar condition including this condition being imposed on the subsequent purchaser.

Printed and bound by Kube, September 2010 


\title{
Self-Reporting Untoward Events to External Controllers: Accounting for reporting failure by a top tier chemical plant ${ }^{1}$
}

\author{
Julien Etienne
}

\begin{abstract}
This paper explores the reasons of hazardous organizations for responding to state rules requesting them to report untoward events to public regulators. The literature on external reporting of untoward events remains remarkably limited, and this paper contributes to it by providing a rare empirical account of the micro-level factors and processes behind reporting failures. It builds on empirical research on a case in the French chemical industry. The paper discusses a reporting failure by addressing principally managers' motivations and how they are shaped by the regulatory context, the regulator-regulatee relationship, and the organization's policies and rules. The paper provides also a vivid picture of patterns of over-compliance, compliance and non-compliance by the same regulated organization, and makes suggestions on the power and limits of self-regulation to help fulfil regulatory goals such as selfreporting of untoward events.
\end{abstract}

\footnotetext{
${ }^{1}$ I wish to thank Michèle Dupré for accepting to share some of her data with me. I also wish to thank Keith Hawkins, Bridget Hutter, Mike Power and anonymous reviewers for their comments and suggestions, which have helped improve the paper considerably. All shortcomings remain my sole responsibility.
} 


\section{Introduction}

In the aftermath of numerous large scale accidents, an information problem has been identified: some of the accidental causes are found to have manifested themselves before, within the organization concerned, or in similar settings elsewhere, in the form of events with minor or no consequences. Then, the question usually raised is: why were the causes of these 'incidents' not addressed, causing re-occurrence and this time with more dramatic outcomes? Many 'man-made accidents' appear to have resulted from such 'failures of foresight' (Turner 1978). For instance, in the follow-up to the BP Texas City refinery disaster in 2005, it was revealed that, of eight previous resembling incidents on site, three had not been reported, and only two had been investigated (CSB 2007: 180). Available information at the time of writing suggests unreported events and unheard warnings also preceded the recent Deepwater Horizon disaster in the Gulf of Mexico (CBS News 2010; Urbina 2010; Donn 2010).

Reporting systems have been introduced to improve attention to untoward events and enable investigation and learning. There are two kinds of reporting systems: either internal, from operators to managers; or external, from organizations to outsiders, and most frequently to public regulators. External reporting is obviously dependent on efficient internal reporting systems, but it likely involves issues and parameters absent from internal reporting and deserves to be studied in its own right.

Rules commanding regulated organizations to disclose 'accidents', 'incidents' or 'near misses' to regulators are integral to numerous risk regulation regimes: nuclear energy, food processing, finance. Yet, there is no comprehensive overview as to whether or how they are complied with. In fact, compliance with self-reporting rules is not easily assessed. The definition of a reportable event can be uncertain or subject to debate: a number of failures appear to be important only after the fact. Definitions for various types of events vary across publications, national regulations, or firms, making comparisons difficult. Also, many untoward events in hazardous organizations do not have consequences perceptible to outsiders, neither loud bang nor smoke. For events with little visibility, regulators are almost completely dependent on regulatees to disclose that sort of information. In other words, incident reporting epitomizes the dependency of controllers on the organizations they control for obtaining information (Vaughan 1990). Hence, it is inherently difficult to know the level of compliance with reporting obligations for different types of events.

A rare glimpse of how a hazardous organization responds to its reporting obligations can be obtained when scholars are fortunate enough to be on site when an untoward event unexpectedly occurs, or shortly afterwards. This is the kind of material I am discussing in this paper. My goal is to reach a satisfactory interpretation for the reporting failure of a regulated firm I was studying in France, after it experienced two successive production incidents.

The paper is structured as follows. After an overview of the literature and a summary of my methods, I sketch the regulatory context in France. I then introduce the organization and the controllers and describe their relationship. Next, I summarize the organization's record in terms of regulatory compliance and its reporting policy. I then turn to the untoward events and discuss various interpretations for the organization's failure to report them. A discussion and conclusion follow. 


\section{State of the art}

Three streams of literature are relevant for the analysis of business compliance with self-reporting rules: the 'safety science' literature; the social science literature on selfreporting; and the literature on business compliance.

The 'safety science' literature has built the argument for reporting systems. The most common representation of the argument is a three-storey pyramid: the tip represents the rare 'major' events, the middle the more frequent 'serious' events, and the bottom the even more frequent 'minor' events and 'near misses' (Johnson 2003: 23). Relying on the idea that these events often share common causes, the literature has emphasized learning from the more frequent and less critical events could help prevent the rare disastrous ones. Most contributions discuss internal reporting (Reason 1997; Sanne 2008; van der Schaaf et al. 1991; van der Schaaf and Kanse 2004), including recent demonstrations that 'near misses' often lead to denial, cover up or procrastination because they are interpreted as success (Dillon and Tinsley 2008; Edmondson et al. 2005), or because they trigger power struggles inside organizations (Starbuck 2009: 927). By contrast, very little can be found in that literature on external incident reporting (but see Uth and Wiese 2004).

More can be found in the social science literature, although except for rare early contributions (Lloyd-Bostock 1988), social scientists' interest on external reporting systems is recent. Economists have strived to model self-reporting decisions by companies (among others: Innes 2001; Kaplow and Shavell 1994; Millock and Zilberman 2006; Pfaff and Sanchirico 2000; Stafford 2007). A few empirical studies using aggregated quantitative data have also been undertaken (Helland 1998; Pfaff and Sanchirico 2004; Short and Toffel 2008; Stafford 2007). Most bear on the American Environmental Protection Agency's (EPA) self-audit policy, which provides incentives for companies to identify, report, and correct violations of environmental regulation. The EPA scheme does not apply to more serious events (EPA 2000: 19623). Most violations self-reported under that scheme have been minor ones (Pfaff and Sanchirico 2004), and companies that self-reported appeared to do so in order to build trust with public controllers and get the latter 'off their back' (Helland 1998; Short and Toffel 2008; Stafford 2007). Two reviews of the British system for reporting untoward events (HSC 2005, 2006; Tombs and Whyte 2008) provide rare empirical assessments of the compliance rate with self-reporting obligations in the industry. According to both reviews, most events except fatalities were under-reported. Major hazard industries were also assumed to be near total compliance with reporting obligations (HSC 2005: 14), a claim presumably based on the proximity between inspectors and these establishments and the view that $\operatorname{trust}^{2}$ in regulator-regulatee relationships is correlated to compliance, cooperation, and transparency. This latter view on trust is widespread in the regulation literature (e.g. Gunningham et al. 2003; Tenbrunsel 1999) and in the literature on internal reporting (Conchie and Donald 2008; Reason 1997; Zhao and Olivera 2006). Besides, several regulatees told the UK Health and Safety Commission (HSC) ${ }^{3}$ they found reporting regulation excessively complex. They were also wary of getting regulators 'on their

\footnotetext{
2 Trust can be defined as a belief that alter will refrain from violating expectations shared between ego and alter even if the opportunity to do so presents itself.

${ }^{3}$ The HSC merged with the Health and Safety Executive (HSE) in 2008.
} 
back' or of being disadvantaged in tendering processes if they complied (HSC 2006). Apart from these few elements, little can be found in the literature on the selfreporting of more than benign events. Besides, there are hardly any studies of selfreporting at the micro level.

The corporate compliance literature is also relevant here, and it has shown that the compliance or non-compliance decision is much more than a cost-benefit assessment. Gunningham, Kagan and Thornton (2003) and Kagan and Axelrad (2000) have studied the influence of the firm's legal, social, and economic environment on responses to regulation. Hoffman (1999) and Rees (1997) have scrutinized the role of norms and peer-pressure on the chemical industry's performances. The role of intraorganizational factors, such as leadership and power struggles (Prakash 2000) and self-regulation (Corneliussen 2005; Hutter 2001a, b; Parker 2002) have also received increasing attention. In sum, business (non)compliance appears to result from multiple and heterogeneous motivations (Simpson 2002: 135). In other words, the literature unlike the economic press - has gone a long way from the most basic model of the firm's response to regulation as a cost-benefit calculus. And yet, propositions to improve compliance with self-reporting rules are frequently based on an instrumental view of business behaviour: for example, the setting up of immunity guarantees (Innes 2001; Parker 2002).

To contribute these three streams of literature, the following study develops a micro level analysis of business non-compliance with self-reporting rules in a hazardous industry, and intends to provide a broad picture of the motivations of the noncompliance decision.

\section{Methodology}

As Parker and Nielsen (2009) have emphasized, explaining business compliance is a notoriously difficult task. The approach taken here is to correlate available evidence of compliance and non-compliance behaviour to the motivations of managers (ibid.: 56-7). However, asking for the regulatee's reasons for performing past actions risks yielding justifications rather than their motivations at the time. Therefore, the paper also reviews data on other parameters and facts from which one may infer reasons for (non)compliance: the regulatory context, the regulator-regulatee relationship, and the rules and policies of the regulated organization.

The data was collected in the context of doctoral research (2005-2009) on regulatory compliance and regulator-regulatee relationships in the field of industrial risk regulation in France. This doctoral research was also part of a larger collective project, and some of the data referred to in this paper were collected with other members of the team. ${ }^{4}$ Access to the establishment studied - a top tier chemical firm had been negotiated between the firm and the head of the research team. Access to regulatory compliance officers was discussed with representatives from the firm, and was agreed for one of the two most relevant regulatory agencies: the Inspection des

\footnotetext{
${ }^{4}$ The data collection was undertaken separately and jointly by Michèle Dupré (University of Lyon, France), Olivier Giraud (CURAPP, University of Picardy, France), Jean-Christophe Le Coze (INERIS, France), and myself.
} 
Installations Classées (IIC). ${ }^{5}$ Hence, data could be gathered from both regulator and regulated organization on the topic of their encounters.

Interviews provided direct or indirect evidence on the motivations of managers, the regulator-regulatee relationship, and the practices of the firm. Semi-directed interviews were carried out with those actors that appeared most likely either to participate in the regulator-regulatee relationship or know about it: in the firm the director (1 interview), the Health, Safety and Environment (HSE) manager (4 interviews), and the safety representative (1 interview); one senior ( 2 interviews) and one junior (1 interview) compliance officer in charge of overseeing the firm at the IIC, and the head of the Environmental Bureau at the local prefecture who stood directly above the latter (1 interview). Another source was the public register of administrative decisions taken by the Inspectorate from 2004 on, available online for members of the public to consult. ${ }^{6}$

Legal and policy documents (statutes, reports, speeches, pamphlets) were reviewed to document the political and regulatory context. Scarce information found on web pages or public reports as well as an interview with two members of the Bureau for Analysis of Industrial Risks and Pollution (BARPI) ${ }^{7}$ provided a general overview of selfreporting in the French industry. Responses to a question on the self-reporting of safety events, included in a questionnaire addressed in 2008 to chemical companies in France, provided another glimpse of the situation. ${ }^{8}$

The research team learned about the events directly from the plant's management, who asked the head of the research team to look into them from a technical point of view. The data collection took place several months after the events: there was no direct observation of the immediate organizational response to the events. The data is therefore limited, and the case of only one particular establishment is discussed. That is too little a basis for uncovering causes for patterns of non-reporting at the macro level. Nevertheless, considering the glaring absence of studies on the self-reporting of untoward events at the micro level, it is a worthy first step in the process of exploring the causes of non-compliance with self-reporting rules.

\section{The regulatory context}

Due to the hazards posed by technologies and substances used, the establishment studied was subject to major hazard regulation, a specific sub-regime within a well developed and mature regulatory framework known as the regime of the installations

\footnotetext{
${ }^{5}$ In France, the enforcement of regulations on industrial risks is split between different agencies: occupational health and safety is the remit of the Inspection du Travail, while other risks, including the prevention of major hazards, the prevention of spills and releases, the management of industrial waste and the rehabilitation of polluted sites are the remit of the Inspection des Installations Classées.

${ }^{6}$ Currently available at http://installationsclassees.ecologie.gouv.fr/rechercheICForm.php

7 BARPI is part of the French Ministry of Environment. It was set up in 1992 to collect accident and incident reports, classify them into a database, and sometimes undertake analyses of events so as to extract common patterns. It has also an important role in defining policy when it comes to reporting and enforcement in response to (non)reporting.

${ }^{8}$ Questionnaires sent in May 2008 to safety representatives of every top tier chemical plant in France $(\mathrm{N}=240)$. The response rate was $32 \%$. The issues explored in the questionnaires were numerous, with the main focus being on regulator-regulatee relationships and compliance motivations.
} 
classées, established mostly in the $1970 \mathrm{~s}^{9}$ and progressively amended by national and European legislations.

The regime of the installations classées claims to prevent productive activities from harming multifarious interests. ${ }^{10}$ Until 2010, it has been divided into two sub-regimes: establishments are either 'declared' or 'authorised'. The lighter regime of 'declaration' applies to low risk establishments which must comply with a list of generic obligations and are rarely, if ever, inspected. The more burdensome regime of 'authorisation' concerns establishments posing greater risks of harm for the interests protected by the law. It combines a licensing procedure and monitoring of industrial activities through periodic inspections carried out by the IIC. Licenses are delivered when operations start, and they are renewed or amended during the course of the installations. License delivery is conditional on the firm's so-called 'safety case': management must demonstrate that hazards have been identified, risks have been evaluated, and either or both have been responded to with safety devices and safety rules. Monitoring involves self-reporting requirements but also inspections, with most of the IIC's resources focused on inspecting the most hazardous of all plants. At the time of enquiry, there were about 650 so-called 'top tier' establishments in France, a third of them belonging to the chemical industry.

As the 'safety case' approach implies, ${ }^{11}$ the French regulation on high hazards is not excessively prescriptive, although inspectors are able to specify the law's general expectations when they interact with regulated organizations. In practice, the discretion left to inspectors to adapt a general regulation to specific cases enables negotiations and compromises in regulatory encounters. However, when dialogue is not enough, inspectors may also formally propose to the préfet the imposition of sanctions. The préfet is the highest-ranking state official in the département, an administrative subdivision of the national territory, ${ }^{12}$ and he or she has the sole power to impose these sanctions on regulated establishments. ${ }^{13}$ Most sanctions are preceded by a notice to act and applied if the latter is unheeded. Sanctions include: seals to forbid access to the establishment or parts of it; travaux d'office, ordering work that the regulated establishment did not undertake itself; suspension of production; closure of the establishment; and consignation de somme, a financial safeguard by which funds to pay for urgently needed work are blocked on the firm's accounts until work is undertaken. Inspectors should also report certain regulatory violations to prosecuting authorities, which may then pursue criminal charges against the owner of the establishment. Criminal sanctions include fines, imprisonment, suspension of production and travaux d'office. These penalties may be publicized as deterrents to other potential offenders.

\footnotetext{
9 Loi no 76-663 du 19 Juillet 1976 relative aux installations classées pour la protection de l'environnement.

${ }^{10}$ Namely: 'the convenience of neighbourhood, or health, security, public safety, or agriculture, or the protection of nature, the environment and the landscapes, or the preservation of sites and monuments as well as elements of the archaeological patrimony' (article L511-1 of the Environmental Code).

${ }^{11}$ The 'safety case' approach is widespread for the regulation of many hazardous industries in Europe, the United States, or Australia (e.g. Hopkins 2002).

${ }^{12}$ France is divided into 100 départements.

${ }^{13}$ Although the proposals by inspectors are generally followed, the préfet is a politico-administrative intermediary that can be and sometimes is directly contacted by regulated firms in order to avert penalties and negotiate compromises.
} 
Table 1: Penalties imposed and authorised establishments in France, 2000-2007

\begin{tabular}{l|rrrrrrrr}
\hline & $\mathbf{2 0 0 0}$ & $\mathbf{2 0 0 1}$ & $\mathbf{2 0 0 2}$ & $\mathbf{2 0 0 3}$ & $\mathbf{2 0 0 4}$ & $\mathbf{2 0 0 5}$ & $\mathbf{2 0 0 6}$ & $\mathbf{2 0 0 7}$ \\
\hline Seals & 15 & 18 & 16 & 13 & 8 & 7 & 4 & 0 \\
Travaux d'office & 26 & 31 & 18 & 27 & 23 & 12 & 23 & 45 \\
Suspension & 168 & 222 & 173 & 150 & 141 & 107 & 90 & 96 \\
Closure & 188 & 42 & 48 & 38 & 47 & 83 & 38 & 41 \\
Consignation de somme & 310 & 296 & 439 & 316 & 279 & 260 & 205 & 237 \\
Notice & 2697 & 3321 & 3046 & 2667 & 2693 & 2981 & 3007 & 3490 \\
Report to prosecuting authorities & 1181 & 1346 & 1354 & 1252 & 1171 & 1326 & 1575 & 1557 \\
\hline Authorised establishments & $\mathbf{6 3 1 7 4}$ & $\mathbf{6 2 3 3 8}$ & $\mathbf{6 4 5 9 7}$ & $\mathbf{6 2 5 2 2}$ & $\mathbf{6 1 3 1 4}$ & $\mathbf{5 8 1 3 6}$ & $\mathbf{5 3 8 4 2}$ & $\mathbf{5 1 0 5 3}$ \\
\hline
\end{tabular}

Source: French Ministry of Environment. The figures relating to penalties and reports to the prosecuting authorities included in Table 1 are for all establishments, both declared and authorised. However, the great majority (between 80 and $90 \%$ ) of penalties and reports are made in relation to authorised establishments. Therefore, the relative frequency of penalties can be better evaluated using the number of authorised establishments as benchmark, rather than the far larger number of declared and authorised establishments (for instance, in 2006, there were about 430,000 declared establishments).

With regard to the more specific issue of self-reporting, the French regulation imposes a general obligation onto all declared and authorised establishments:

the owner of an establishment declared or authorized must report at the earliest convenience to the Inspection des Installations Classées the accidents or incidents occurring as a result of operating the establishment, which are likely to harm the interests mentioned at article L.511-1 (Article R512-69, Environmental Code)

Failure to report is a criminal offence subject to a minimum fine of $€ 1500$, and the Ministry demands that all cases be referred to the prosecuting authorities by inspectors.

In practice, central administrative authorities consider that three types of events should be reported to the IIC: accidents, incidents, and presque accidents (near misses). Accidents are defined by a combination of physical 'effects' (heat, blow, pressure) and significant 'consequences' (i.e. damage or harm). Incidents combine effects with non-significant consequences, although what is and is not 'significant' is itself a matter of case-by-case appreciation. Presque accidents refer to cases where an imminent accident was stopped before any effect or consequence could materialize (interview BARPI). In parallel, the courts consider reporting to be obligatory without regard for the actual consequences of the event. Therefore, even events which appear afterwards to have had no consequences must be reported (Cour de Cassation, Chambre Criminelle, 4 Oct. 2005).

Additional requirements have been introduced in a law of 30 July 2003 (Law no. 2003-699). Articles 2 and 14-2 extended the list of recipients of reports to a forum where representatives from the population living or working nearby interact with inspectors and representatives from the establishment, ${ }^{14}$ and to the college of worker representatives legally constituted in every company with more than 25 employees. ${ }^{15}$

\footnotetext{
${ }^{14}$ Known as CLICs (Comité Local d'Information et de Concertation), these forums had yet to be created at the time of the enquiry.

${ }^{15}$ This college is known as CHSCT (Comité d'Hygiène, Sécurité et Conditions de Travail).
} 
Finally, a joint initiative of BARPI and the French chemical industry body (Union des Industries Chimiques, UIC) launched at the end of 2006 has tried to convince chemical establishments to openly communicate about untoward events, especially when the latter are perceptible to outsiders. The UIC has linked this requirement in participation to the Responsible Care programme, an international self-regulation scheme of the chemical industry (Rees 1997).

There is no readily available information on how many failures to report have been prosecuted. Only a few cases have been publicized in the media, including a spectacular spill of oil originating from the refinery La Mède, property of Total. In that case failure to report the spill to the Inspectorate was fined €2'000 (Trib. de police, Martigues, 8 June 2007). More generally, there are no public statements on the level of compliance with the self-reporting rule. All reported events tend to be aggregated in a national database (called ARIA), with little distinction of kind or type. In a survey undertaken in 2008 and covering a number of issues, I had asked respondents (all of them representatives of top tier chemical plants in France) their views on self-reporting incidents to the IIC if such events were to take place in their premises. Only $7.9 \%$ of the respondents answered they would immediately self-report the incident and $5.3 \%$ answered they would not report it. The remaining $86.8 \%$ answered they would rather make an internal assessment to begin with, and later decide whether to report it or not. An overview of the ARIA database suggests that an important criteria for decisions to report is the visibility of the event for outsiders. ${ }^{16}$

\section{The parties to the regulatory encounter}

The establishment studied was a chemical processing plant. It was French until the mid 1980s and had experienced one major incident before it was bought by an American company that I will refer to as 'US Chem'. US Chem had a hundred or so subsidiaries globally. The plant itself was of average size (about 350 employees) in a sector dominated by small and medium enterprises (SMEs). ${ }^{17}$ It was in growth and one of the biggest employers in an area where unemployment was high. ${ }^{18}$ It produced principally a range of polymers used in different domains and for different purposes: the food industry, packaging, paints, nuclear industry, or water treatment.

The organization was resourceful and proactive. It participated in a number of voluntary certification schemes (ISO, OHSAS). It was also an early participant in the Responsible Care programme in France, and a leader on improving the industry's response to the risks of transporting dangerous goods. The establishment was operating with detailed corporate standards and was inspected every three months by

\footnotetext{
${ }^{16}$ In 2006, the French database collected 135 reports of events having taken place in chemical industries. Of these 135 events, 108 were very likely to have been visible to outsiders since they involved a fire or explosion, affected people outside the plant, raised enough concern within the plant to call the fire brigade to intervene, or had other consequences visible to outsiders (coloured river, dead fish, smoke etc.), or involved fatalities.

${ }^{17}$ According to the website of the chemical industry body UIC, $78 \%$ of French chemical enterprises in 2006 had less than 25 employees.

${ }^{18}$ According to the plant's director, this was a reason why the plant was well perceived in the neighbourhood: 'Let's say we are well accepted or tolerated given what the job market is like'.
} 
inspectors from the parent company. ${ }^{19}$ The corporate standards and the enforcement tools used internally were partly inspired by American state regulation.

We are an American company. ... [US Chem] standards are almost a copypaste of OSHA ${ }^{20}$ regulation. So it is very precise. ... French regulation does not come to that level of detail. (HSE manager)

National regulations from countries where US Chem had subsidiaries were also an influence, albeit a secondary one. The influence of American regulation on the company's self-regulation was also apparent in its internal enforcement practices, compared in the following quote to those of the US EPA.

The EPA observes a violation: boom. It's not a notice. It's a fine. ... That's very inciting. And so [US Chem] is implementing this at the level of its production units. The same policy. Although behind there are no fines. ... [If] we do not satisfy a client he will go somewhere else. That's the penalty. (HSE manager)

This quote refers to US Chem's policy to put its production units in competition, allocating shares of client orders to the most effective ones and to those that comply best with corporate standards. As a result of this internal competition between production units, if the plant fails to deliver as planned or if it fails to comply with corporate standards, it would then lose orders as well as resources in favour of another unit. The establishment had thus benefited from transfers of activity from two other US Chem subsidiaries. It gained a leading position in its production segment, although it remained in a marginal position compared to the global production set of US Chem.

Substantial pressure was also felt at the enforcement agency, a consequence of the AZF disaster in the southern city of Toulouse, when a chemical plant exploded in September 2001 killing about 30 people and generating material destruction on a large scale. Following public outcry, the agency's policy changed in favour of a tougher stance on the industry. More staff were recruited, the IIC restructured, its internal rules modified (Etienne 2007), and the workload increased substantially. Inspectors felt also they were more at risk of being prosecuted following an accident after fellow inspectors had been prosecuted twice in the 1990s and 2000s.

Point persons for controllers were the director of the plant and more frequently, the HSE manager. They had been interacting repeatedly with two inspectors, both of them engineers by training, who were monitoring a number of establishments. The most senior of the two was also the point person for the HSE manager. For the last six years before the enquiry, and with the exception of the younger inspector who had been in post for only a short period of time, regulator-regulatee interactions had been occurring between the same persons, in fact 'repeat players' (Galanter 1974).

\footnotetext{
${ }^{19}$ That implied a visit of five auditors for a week.

${ }^{20}$ Occupational Safety and Health Act, 1996.
} 


\section{The regulator-regulatee relationship}

The relationship between the regulated organization and the IIC was generally peaceful and informal. Until the issuance of a single warning in 2008, the establishment had not received any notice nor formal penalties in 15 years. Inspectors were not keen on circumventing their contact persons at the plant in order to obtain information: they did not attend the meetings held by safety representatives to discuss health and safety problems in the establishment in spite of being regularly invited. Inspectors also remained responsive to informal requests from their contact persons in the establishment. Remarkably, on all of these aspects, inspectors did not follow repeated demands by the Ministry of Environment that they should be more distant and formal. ${ }^{21}$

Similarly, the establishment had always discussed compliance issues directly with the inspector and had not contacted the prefecture or the media, although this was not an uncommon way for similar establishments to push for a better deal. Dialogue was seen as easy because both parties shared a common background: 'he's an engineer, it's easy to discuss with him' (HSE manager). There were clear differences in resources between the IIC and the establishment, the latter having far more competences to address safety issues. However, managers did not push their advantage, and had an open and responsive attitude, one they would keep as long as regulation did not threaten the plant's development. ${ }^{22}$

In sum, both sides had a very positive idea of their relationship: 'transparent' (Senior Inspector; HSE manager), 'one respects the other' (Senior Inspector), 'one has confidence' (Senior Inspector), 'everything is going on very well' (HSE manager, plant director), 'there are no pitfalls' (Senior Inspector).

\section{The organization's responses to state regulation}

To external observers and regulators, the regulated plant appeared to be both a compliant and safe organization.

In addition to a record of 15 years of continuous production without notices or penalties, records showed it had not experienced any minor or major incident for the last 20 years or so. For one of the inspectors, the plant's performance was what you would expect from an American company.

That is the culture of American groups. One feels that behind there is a rather voluntary policy. ... [O]ne feels they have a safety culture and that they like to have plants that are clean regulation wise. (Junior Inspector)

\footnotetext{
${ }^{21}$ In the late 1990s the Ministry had imposed new rules to tackle what was perceived to be a pattern of too close relationships between inspectors and regulated organizations. That, however, 'did not change anything' (HSE manager): dialogue continued.

${ }^{22}$ The slowness of regulatory procedures, especially permit renewals, was seen as a potential problem: '[If a new permit procedure had had to be undertaken as the result of a transfer of activity from one other unit to the plant,] I think we would have gone further, we would have kicked over the traces. Otherwise the activity would have gone elsewhere' (HSE manager).
} 
Managers were indeed concerned about avoiding penalties. ${ }^{23}$ The director and HSE manager also considered corporate standards to be more detailed and demanding than major hazard regulation, therefore the impact of the latter on the firm was minimal. For instance, changes triggered by regulatory inspections were 'minor stuff' (HSE manager). For inspectors as well, the company had been proactive and was therefore frequently ahead of major hazard regulation.

However, the regulated organization did not do as well with regulation on the prevention of spills and releases, the management of industrial waste and the rehabilitation of polluted sites, also enforced by the IIC and the same individual inspectors. For some time, US Chem had been in breach of the limits for toxic releases in the atmosphere and pollutants in the nearby river. The Inspectorate was clearly aware but issued neither notices nor penalties, only recommendations.

With regard to spills and discharges in water, [US Chem] standards are much less precise than public regulation. Since forever we get recommendations in terms of air releases of toxic products. ... in terms of releases in water, there is nothing, there's a gap in [US Chem] standards. ... There French regulation has an impact on us. (HSE manager)

In terms of air pollution, non-compliance was acknowledged by the IIC but not penalized. In terms of water pollution, standards had been negotiated in order to accommodate the plant's production targets.

HSE manager: ... there were standards for releases in the river that we would not have been able to comply with ... We realized we would not make it so we presented a case saying: there, we won't be able to make it. So that was the object of discussions with the IIC at the time, and there were also the navigation services that came in, and it led to a new document, a complementary one, which deleted a few mistakes from the former document, and introduced new limits for releases.

Interviewer: $\quad \ldots$ that were compatible with the activity?

HSE manager: Yes, that's it. ... That was not done on a table corner. ... We had included release standards that were a function of the river's flow.

Remarkably, these different responses to state rules were correlated to corporate standards. On major hazards, US Chem standards were more detailed and more demanding than public rules, therefore overall performances on these issues were good or better than regulatory expectations. However, on releases in the air and water environment, state rules clearly exceeded corporate standards, and were either the subject of negotiations to accommodate the former to production needs, or they were repeatedly violated.

\footnotetext{
23 'For now I have never had any notice. I hope it will last like that for a long time' (HSE manager). 'I am convinced that there are businesses whose goal is to wait for the notice to do something ... That is not our case.' (HSE manager)
} 


\section{The organization's reporting policy}

The plant was required by law to communicate various information to the Inspectorate, and chiefly hazard studies when submitting applications for renewing its authorization. The plant was praised by the Inspectorate for taking this latter requirement seriously:

There's always a tendency for safety cases to be administrative paperwork rather than the studies the regulation requires. ... At [US Chem] when they do a case it's a study and not a file of administrative requirements that had to be done carelessly to make the administration content. (Inspector)

Managers also self-reported minor problems: polluted sites, problems in complying with certain requirements, or modifications to the premises undertaken without proper authorization. Progress on these matters was achieved informally, the Inspectorate privileging dialogue over retribution, or simply failing to react. In any case, selfreporting minor problems apparently contributed to the company's image of transparency.

One feels that, fundamentally, each time, these guys strive for transparency. I do think this is the case of [US Chem] ... and it's not always the case with chemical industries. (Senior Inspector)

This reputation was reinforced by the company's proactive communication strategy towards residents, elected officials, and NGOs recruited in a forum set up by the company. Managers also avoided interacting with members of the public in other terms than their own. For instance, on a public meeting that might have been organized by the city mayor to discuss safety issues raised by the plant:

I went to see the mayor, and I asked him what he was going to do. ... After discussion and further thinking he told me that we communicate enough. So he does not see the point of organizing this public meeting ... because he fears that there would be some... trouble-makers I would say, who would completely tear apart the meeting. That is the big risk ... that we offer to some, and in particular to people not always well intentioned, to have others talk about them and to make a lot of harm to French industry. (Director)

This reveals a careful management of the information released to outsiders so as to always present the plant in a favourable light. ${ }^{24}$ The establishment resembled the 'environmental strategists' identified by Gunningham et al. (2003): proactive firms working on their relationship with outsiders to win and maintain a reputation for honesty and reliability, but carefully withholding potentially risky information. It is in light of these various traits that the organization's management of two successive events should be considered.

\footnotetext{
${ }^{24}$ The plant had experienced a major incident in the early 1980s before it was bought by US Chem: 'It's important to say it ... must not put that on the back of [US Chem].' (HSE manager)
} 


\section{The events and the organization's response}

Both events originated inside a process vessel. An agitating device that was to control certain parameters of the chemical reaction failed in the first case due to a power cut, and in the second due to a failure of a software component, the chemical reaction became uncontrollable. However, the rest of the process chain was well designed: substances ended up in a catch tank, ${ }^{25}$ and part of the (toxic) gas produced in the process was filtered through a fume scrubber. ${ }^{26}$ Only a small quantity of gas was eventually released. These events share similarities with numerous other significant incidents in the industry (HSL 2003). They brought evidence of a flaw in the design that engineers had apparently not detected. Therefore, had the agitator's failure been combined with failures of other critical safeguards, any one of these incidents could have contributed to a 'normal accident' (Perrow 1999): a release of a large quantity of toxic gas (Fig. 1).

Figure1: Schematics of an accidental scenario of loss of containment, and the safety barriers designed to prevent it (in green), applicable to the process where the events took place (in Le Coze and Dupré 2006)

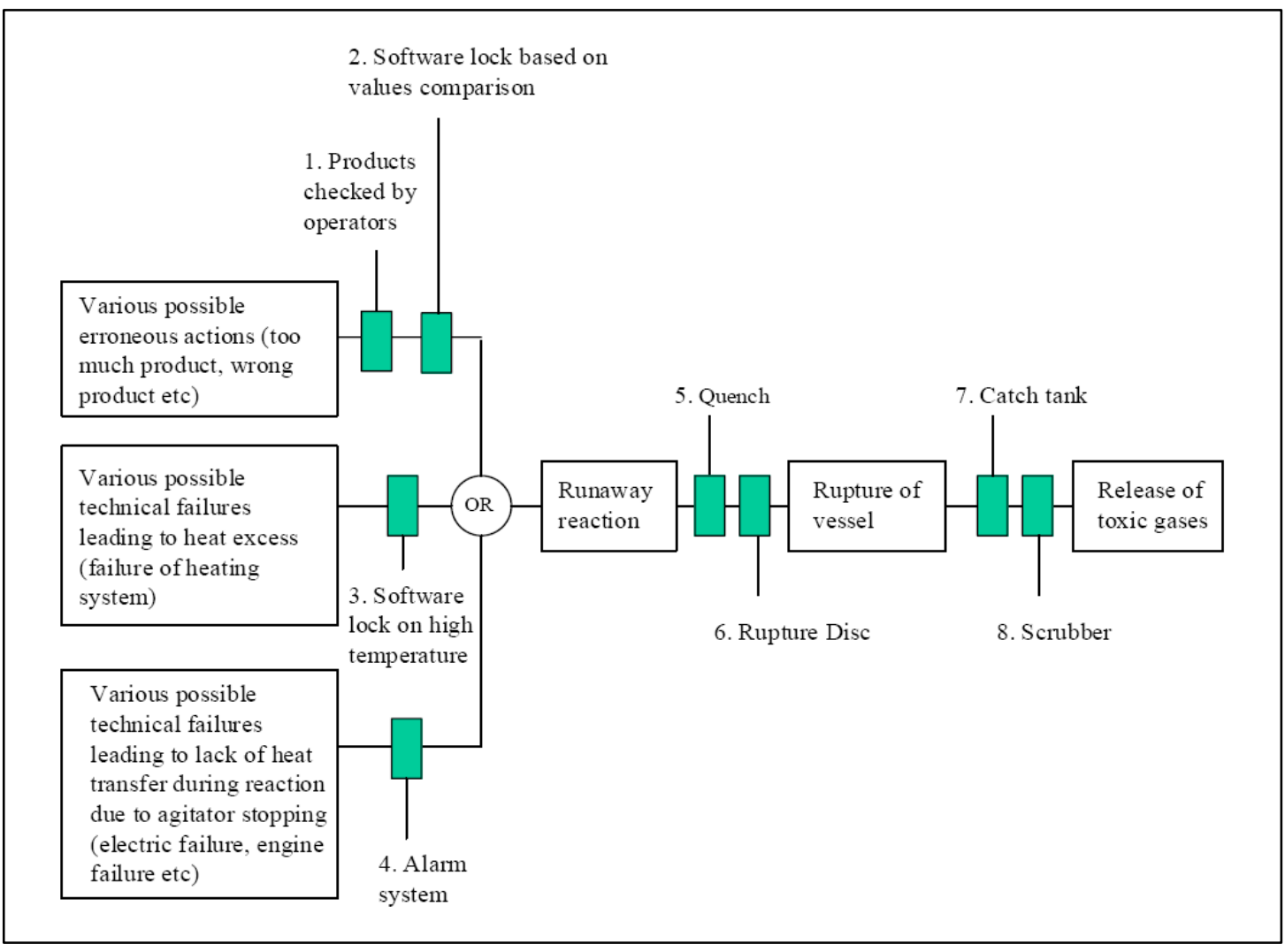

These were clearly what French regulatory authorities call incidents, since there had been 'effects' (rising heat and excessive pressure), but only small 'consequences'.

\footnotetext{
${ }^{25}$ A catch tank is a volume designed for collecting substances under pressure in case of an uncontrollable reaction.

${ }^{26}$ A fume scrubber operates like a filter for the treatment of gas released in case of high pressure in the catch tank.
} 
However, these events also had the characteristics of a 'near miss' as a clear accidental path had been taken but with the accident averted.

Several things happened in the follow-up of these events:

- Repairs were carried out to replace parts that had been damaged such as ruptured discs, and to resume production shortly.

- The events were reported internally and at group level, and recorded in an internal registry.

- The parent company's response to the event report was to send a safety expert from the United States to France who provided training in root cause analysis ${ }^{27}$ and then returned home. The training was not built upon. It was almost as if it had never happened (Dupré et al. 2009).

- The head of the research team was asked to begin a consultancy mission to elaborate technical solutions to prevent a similar failure.

- Last but not least, none of the two events - which had not raised concern from the part of outsiders - was reported to the Inspectorate.

There is little doubt that managers at the plant knew of their regulatory obligation to report the events. During fieldwork I had had the opportunity of finding them well versed in their legal obligations but also in the limits of these same obligations. For instance, the plant's director corrected me once for mentioning inaccurately the particulars of a new obligation voted in 2003, requesting top tier establishments to communicate information to the public. Similarly, the HSE manager could spell out the differences between corporate standards and state rules on a variety of issues, and mentioned obligations that did not make much sense in terms of risk but had to be complied with nonetheless. ${ }^{28}$ Therefore, the hypothesis of non-compliance due to ignorance or misunderstanding does not appear to be supported there, although it may be relevant in many other instances of non-reporting.

\section{Interpreting non-compliance}

Several lines of interpretation can be substantiated. They are not necessarily exclusive to each other.

\section{Excessive optimism}

Interviews carried out within the organization by M. Dupré and J.C. Le Coze revealed that several members of the organization saw the events in an optimistic way in that they were viewed as a proof of strength rather than weakness. Although they occurred successively on the same spot and therefore appeared likely to recur in the near future,

\footnotetext{
${ }^{27}$ Root cause analysis refers to a range of investigation techniques, principally reactive ones, to see beyond the symptoms or immediately visible causes of an incident, and to identify the many causes that may have contributed to it, such as problems of design (including 'barriers'), organization, environment, or management.

28 'There's a unit operating illegally. It isn't much, it is a cooling unit. It's been added to the application for authorization that we made ... But that's been operating completely illegally since 2002-2003. The IIC knows it. But risks on these units are non-existent. ... But it's one of the categories of installations classées. I should have an authorization, and I don't have one' (HSE manager).
} 
the events had also been unsolicited tests for the robustness of the safety system (catch tank, rupture disks, scrubber). A positive story had imposed itself, denying the problems uncovered.

Thus, the failure to report the events to the Inspectorate might have been a nondecision (Anderson 2000). Without direct observations of the events unfolding within the organization at the time, it is impossible to confirm or rebutt this interpretation with direct evidence. However, the decision to enroll outsiders in a consulting mission to find solutions to the weak point uncovered by the incidents contradicts the "nondecision' thesis. Remarkably, the intervention of the research team in the premises was clearly taken as an opportunity by some managers to also address the problems raised by the events. The intervention of an expert from the parent company had failed to trigger such a reflection, suggesting that actors within the organization resisted the attempts of others to challenge the design head-on. In sum, rather than a community plagued by groupthink, the organization appeared divided in the way it made sense of the incidents. Some of the power struggles that Prakash (2000) mentions as important factors behind responses to regulation may have been at play.

\section{'Not in our culture'}

One of the explicit reasons for not reporting the incidents was that it was "not in [the organization's] culture to report that' (HSE manager). Corporate standards required internal reporting of untoward events, but did not require external reporting. In other words, the reporting failure fits the pattern apparent in the organization's responses to other state rules: all state rules covered by corporate standards were complied with. For those that were not, compliance was negotiated, or there was no compliance. I will come back to this later.

\section{Concerns over the regulator's response}

The second explicit reason for not reporting was a reference made by the HSE manager to another case. The HSE manager knew of a twin plant in another region of France, also owned by US Chem, where an event had been reported to the local inspector. The inspector's response had been to suspend production. The inspector's hierarchy had then refused for a while to authorize resumption of production. Thus, self-reporting was presented as too costly for it could yield disruption to production output. $^{29}$

The case quoted by the HSE manager was actually after the events and the reporting failure it served to justify. The evidence rather suggests that managers did not consider there was much at risk if the inspector learned about the events well after they had occurred: outsiders (the research team) had been informed, and the events were also registered in the internal registry of technical incidents which is accessible to the Inspectorate. This was confirmed after the research project formally ended when a quasi identical event took place and was reported to the inspector not by the management but by an operator. The HSE manager then justified his failure to report the event to the inspector and avoided penalties, benefiting from the inspector's

\footnotetext{
${ }^{29}$ Similarly, one of the respondents to the survey analysis mentioned earlier added on the questionnaire that he would 'never again' report an incident, and that his most important rationale when responding to regulation was to avoid 'the financial costs of a suspension of production'.
} 
attention to the company's goals and from relational 'regulatory capital'

(Gunningham et al. 2003: 51) accumulated in numerous repeated encounters.

I had to use two lines of argumentation. According to corporate [standards], this is not an incident with an environmental impact since everything was contained. I also used in my discussion with the inspector the case of our other plant [where activity had been suspended following self-reporting]. ... Fortunately my relations with him were not strained. (HSE manager)

The example of the twin plant where production was suspended following reporting hints also at the importance managers gave to production goals. Prioritizing production was institutionalized in US Chem's policy of competition between production units, and it was clearly at play in the negotiation of more lenient standards, as mentioned earlier.

\section{Protecting the firm's reputation}

Finally, not reporting the incidents was also in line with the more general reporting policy of the plant described earlier. Managers were protecting the plant from possibly hostile outsiders, and they were also protecting the image of a very safe organization that they had built over the years. Indeed, not reporting the incidents could help sustain the organization's trustworthiness, since trust is produced and sustained by 'signs' or 'signals' (Bacharach and Gambetta 2001; Lindenberg 2000): parties show each other that they are worthy of the other's trust and, correlatively, avoid showing that they are unworthy of it.

\section{Discussion}

In agreement with the business compliance literature and contrary to the common view of business motivations, the empirical evidence suggests that a mix of internal (power struggles, optimistic sensemaking, organizational rules and penalties, production goals) and external (reputation, costs of bad publicity by hostile outsiders, costs of a negative response by the inspector) factors contributed to the organization's failure to report. The relative weight of each of these factors cannot be assessed easily. However, the evidence suggests that the organization's behaviour fitted into a pattern of reporting practices and responses to regulation, themselves linked to the regulatory context, the relationship with the regulator, and the company's self-regulation.

The correlation between the degree of overlap between corporate standards and state rules on the one hand, and the response to state rules on the other hand is striking. There was a tendency to challenge state rules if they went beyond or contradicted corporate standards. Self-reporting events to regulators, just like compliance with other obligations that did not fit in the plant's self-regulation, appeared to depend on much weaker supports than obligations and expectations institutionalized in corporate rules.

I would like to suggest the following interpretation for this pattern. It is well known that individuals cannot attend equally to all issues. Rather, issues are attended selectively. Organizations tend to be structured and organizational rules tend to be developed so as to channel attention on specific issues (Rerup 2009). This is, for 
example, one of the effects of institutionalized competition between production units to focus managers' attention on production problems and targets. Similarly, internal audits repeatedly focus the personnel's attention on corporate standards and the necessity to comply with them. In other words, organizational processes do not only affect cognition by allocating attention to certain aspects and away from others, they also influence motivations. Such an interplay between motivation and cognition has been hypothesized and demonstrated in social psychology experiments (Kruglanski et al. 2002). There is no reason to think that the influence of state regulation on the motivations of regulatees may not operate in the same fashion. Inspections, threats of penalties or promises of rewards also attempt to capture the attention of regulatees and therefore have some influence on their motivations (Etienne 2010).

Hence, individuals within organizations are subject to at least two different streams of rules and enforcement practices, both competing for a limited resource: attention. This impacts on the motivations to respond to expectations formulated in either corporate or state rules. And it boils down to a simple and widespread observation: given the limited resources of external controllers to oversee an organization's premises, there is little chance that they could be as successful as organizations themselves in capturing the attention and structuring the motivations of individuals within these organizations. This explains why operators within organizations are often unaware or not conscious of state rules that apply to them. But this also supports the idea that selfregulation could solve problems of regulatory compliance: by including regulatory goals in corporate rules, self-regulation might make regulatory goals a prominent aspect in the set of motivations pursued by individuals working within business organizations (Hutter 2001).

However, as the case study suggests, there is a downside: if corporate self-regulation does not overlap with state regulation, then there will often be only weak motivations to comply with state rules exceeding or contradicting corporate rules. To comply with corporate standards was an important goal for the staff at the plant, and so was the goal to keep production going, because both were strengthened by very detailed organizational rules, frequent training, and processes of monitoring and enforcement. Even the goal to keep outsiders at bay was in a way institutionalized in organizational rules, with established procedures and a forum with outsiders. By contrast, the competing goal to comply with more demanding state rules only came afterwards, receiving less attention and effort. For example, state rules on releases or incident self-reporting were responded to with only weakly positive or negative motivations.

\section{Conclusion}

A case study can only be a first step to understanding such a phenomenon as compliance or non-compliance with incident self-reporting rules. Yet, this paper has contributed in its own way to three different streams of literature and can pave the way for more extensive research into the issue. This first attempt to interpret the motivations behind failure to self-report incidents has come to at least three conclusions.

- As other forms of business (non)compliance, responses to self-reporting rules appear to be the product of multiple factors, both internal and external to the 
organization. Accordingly, motivations to self-report untoward events or not can be numerous. It is remarkable that the fear of penalties linked to a reporting failure appeared negligible in comparison with other factors.

- Self-reporting appears to have an ambivalent rather than straightforward relationship with 'trust'. On the one hand, self-reporting positive information (e.g. hazard studies) and mildly negative information (small violations, small problems that have been solved) can contribute to a firm's trustworthiness. On the other hand, publicity of untoward events that appear to have more serious implications may be seen as reputational damage. Therefore, organizations that willingly self-report positive or mildly negative information may be also willingly hiding information on more important events such as near misses.

- Paradoxically, motivations for complying with self-reporting rules may be too weak because those for complying with corporate standards may be strong. When self-regulation is operating successfully, then state rules exceeding or conflicting with organizational rules may be responded to opportunistically, and therefore the level of compliance with state rules may be low.

Whether these conclusions may hold for a greater number of cases is a question further empirical research will answer. These conclusions may lead to a tentative recommendation for practitioners: to improve self-reporting of untoward events by businesses to external controllers, external reporting rules should become integral to the industry's corporate standards as, for instance, in the Norwegian giant energy company Statoil (Berentsen and Holmboe 2004). 


\section{References}

Anderson, C.J. (2000) 'The psychology of doing nothing: forms of decision avoidance result from reason and emotion', Psychological Bulletin 129(1): 139-67.

Bacharach, M. and D. Gambetta (2001) 'Trust in signs', in K.S. Cook (ed.) Trust in Society. New York: Russell Sage Foundation.

Berentsen, R. and R.H. Holmboe (2004) 'Incidents/accidents classification and reporting in Statoil', Journal of Hazardous Materials 111(1-3): 155-9.

CBS News: 60 Minutes (2010) 'Blowout: the Deepwater Horizon disaster', CBS 16 May. www.cbsnews.com/stories/2010/05/16/60minutes/main6490197.shtml.

Conchie, S.M. and I.J. Donald (2008) 'The functions and development of safetyspecific trust and distrust', Safety Science 46: 92-103.

Corneliussen, F. (2005) 'The impact of regulations on firms: a case study of the biotech industry', Law \& Policy 27(3): 429-49.

CSB (2007) Investigation Report: Refinery Explosion and Fire, BP, Texas City, March 23, 2005. Washington (DC): US Chemical Safety and Hazard Investigation Board.

Dillon, R.L. and C.H. Tinsley (2008) 'How near-misses influence decision making under risk: A missed opportunity for learning', Management Science 54(8): 1425-40.

Donn, J. (2010) 'AP investigation: oil rig blowout preventers have a long history of breaking down at other wells', Associated Press, 8 May.

Dupré, M., J. Etienne and J-C. Le Coze (2009) 'L'interaction régulateur régulé: Considérations à partir du cas d'une entreprise Seveso II seuil haut', Annales des Mines. Gérer et Comprendre 97: 16-27.

Edmondson, A.C., M.A. Roberto, R.M.J. Bohmer, E.M. Ferlins and L.R. Feldman (2005) 'The recovery window: organizational learning following ambiguous threats', in W.H. Starbuck and M. Farjoun (eds.) Organization at the Limit: Lessons from the Columbia Disaster. Oxford: Blackwell.

EPA (2000) 'Incentives for self-policing: discovery, disclosure, correction and prevention of violations', Federal Register 65(70): 19618-27.

Etienne, J. (2007) 'Reorganising public oversight of high-risk industries in France: a reliability analysis of permitting', Journal of Contingencies and Crisis Management 15(3): $144-56$.

Etienne, J. (2010) 'Compliance theory: a goal framing approach', presented at the Third Biennal Conference of the ECPR Standing Group on Regulatory Governance, 17-19 June 2010, Dublin, Ireland. http://regulation.upf.edu/dublin-10-papers/3I3.pdf.

Galanter, M. (1974) 'Why the "haves" come out ahead: speculations on the limits of legal change', Law \& Society Review 9(1): 95-160.

Gunningham, N., R.A. Kagan and D. Thornton (2003) Shades of Green. Business, Regulation, and Environment. Palo Alto (CA): Stanford University Press. 
Helland, E. (1998) The enforcement of pollution control laws: inspections, violations, and self-reporting', Review of Economics and Statistics 80(1): 141-53.

Hoffman, A.J. (1999) 'Institutional evolution and change: environmentalism and the US chemical industry', Academy of Management Journal 42(4): 351-71.

Hopkins, A. (2002) Two models of major hazard regulation: recent Australian experience', in B. Kirwan, A. Hale and A. Hopkins (eds.) Changing Regulation: Controlling Risks in Society. Oxford: Pergamon.

HSC (2005) The Review of the Reporting of Injuries, Diseases and Dangerous Occurrences Regulations 1995 (RIDDOR). London: Health and Safety Commission.

HSC (2006) Background to RIDDOR Requirements, the Review and Findings from Stage One. HSC/06/40.

www.hse.gov.uk/aboutus/meetings/hscarchive/2006/250706/c40b.pdf.

HSL (2003) Loss of Containment Incident Analysis. Sheffield: Health and Safety Laboratory.

Hutter, B. (2001a) Regulation and Risk: Occupational Health and Safety on the Railways. Oxford: Clarendon Press.

Hutter, B. (2001b) 'Is enforced self-regulation a form of risk taking?: The case of railway health and safety, International Journal of the Sociology of Law 29: 379-400.

Innes, R. (2001) 'Violator avoidance activities and self-reporting in optimal law enforcement', Journal of Law, Economics, \& Organization 17(1): 239-56.

Johnson, C. (2003) Failure in Safety-Critical Systems: A Handbook of Incident and Accident Reporting. Glasgow University Press.

Kagan, R.A. and L. Axelrad (eds.) (2000) Regulatory Encounters. Multinational Corporations and American Adversarial Legalism. Berkeley (CA): University of California Press.

Kaplow, L. and S. Shavell (1994) 'Optimal law enforcement with self-reporting of behavior', Journal of Political Economy 102(3): 583-606.

Kruglanski, A.W., J.Y. Shah, A. Fishbach, R. Friedman, W. Young Chun and D. Sleeth-Keppler (2002) 'A theory of goal systems', in M.P. Zanna (ed.) Advances in experimental social psychology, Vol. 34. San Diego (CA): Academic Press.

Le Coze, J-C. and M. Dupré (2006) 'How to prevent a normal accident in a highly reliable organization. The art of resilience, a case study in the chemical industry', in E. Hollnagel (ed.) Proceedings of the Second Resilience Engineering Symposium. Paris: Presses de l'Ecole des Mines.

Lindenberg, S. (2000) 'It takes both trust and lack of mistrust: the workings of cooperation and relational signaling in contractual relationships', Journal of Management and Governance 4: 11-33. 
Lloyd-Bostock, S. (1988) Legalism and Discretion: A Study of Responses to Accidents and Accident Information Systems in the Occupational Safety and Health Administration (OSHA), USA. Oxford: Centre for Socio-Legal Studies.

Millock, K. and D. Zilberman (2006) Collective Penalties and Inducement of SelfReporting. Cahiers de la Maison des Sciences Economiques 48. Paris Panthéon Sorbonne University.

Parker, C. (2002) The Open Corporation: Effective Self-Regulation and Democracy. Cambridge University Press.

Parker, C. and V. Nielsen (2009) 'The challenge of empirical research on business compliance in regulatory capitalism', Annual Review of Law and Social Science 5: $45-70$.

Perrow, C. (1999) Normal Accidents. Living with High-Risk Technologies. 2nd ed. Princeton University Press.

Pfaff, A.S.P. and C.W. Sanchirico (2000) 'Environmental self-auditing: setting the proper incentives for discovery and correction of environmental harm', Journal of Law, Economics, \& Organization 16(1): 189-208.

Pfaff, A.S.P. and C.W. Sanchirico (2004) 'Big field, small potatoes: an empirical assessment of EPA's self-audit policy', Journal of Policy Analysis and Management 23(3): 415-32.

Prakash, A. (2000) Greening the Firm. The Politics of Corporate Environmentalism. Cambridge University Press.

Reason, J. (1997) Managing the Risks of Organizational Accidents. Aldershot: Ashgate.

Rees, J. (1997) 'Development of communitarian regulation in the chemical industry', Law \& Policy 19(4): 477-528.

Rerup, C. (2009) Attentional triangulation: learning from unexpected rare crises', Organization Science 20(5): 876-93.

Sanne, J.M. (2008) 'Incident reporting or storytelling? Competing schemes in a safety-critical and hazardous work setting', Safety Science 46: 1205-22.

Short, J.L. and M.W. Toffel (2008) 'Coerced confessions: self-policing in the shadow of the regulator', Journal of Law, Economics \& Organization 24(1): 45-71.

Simpson, S.S. (2002) Corporate Crime, Law, and Social Control. Cambridge University Press.

Stafford, S.L. (2007) 'Should you turn yourself in? The consequences of environmental self-policing', Journal of Policy Analysis and Management 26(2): 305-26.

Starbuck, W.H. (2009) 'Cognitive reactions to rare events: perceptions, uncertainty, and learning', Organization Science 20(5): 925-37.

Tenbrunsel, A.E. (1999) 'Trust as an obstacle in environmental-economic disputes', American Behavioral Scientist 42(8): 1350-67. 
Tombs, S. and D. Whyte (2008) 'A crisis of enforcement: the decriminalisation of death and injury at work', Briefing 6. King's College London: Centre for Crime and Justice Studies. www.crimeandjustice.org.uk/opus685/crisisenforcementweb.pdf.

Turner, B.A. (1978) Man-Made Disasters. Oxford: Wykeham.

Urbina, I. (2010) 'BP used riskier method to seal oil well before blast', New York Times, 26 May.

Uth, H-J. and N. Wiese (2004) 'Central collecting and evaluating of major accidents and near-miss-events in the Federal Republic of Germany - results, experiences, perspectives', Journal of Hazardous Materials 111: 139-45.

Schaaf, T. van der, D.A. Lucas and A.R. Hale (eds.) (1991) Near Miss Reporting as a Safety Tool. Oxford: Butterworth-Heinemann.

Schaaf, T. van der, and L. Kanse (2004) 'Biases in incident reporting databases: an empirical study in the chemical process industry', Safety Science 42: 57-67.

Vaughan, D. (1990) Autonomy, interdependence, and social control: NASA and the space shuttle Challenger', Administrative Science Quarterly 35: 225-57.

Weick, K.E., K.M. Suttcliffe and D. Obstfeld (2005) 'Organizing and the process of sensemaking', Organization Science 16(4): 409-21.

Zhao, B. and F. Olivera (2006) 'Error reporting in organizations', Academy of Management Review 31(4): 1012-30. 